\title{
Extended Pedigree with Multiple Cases of XX Sex Reversal in the Absence of SRY and of a Mutation at the SOX9 Locus
}

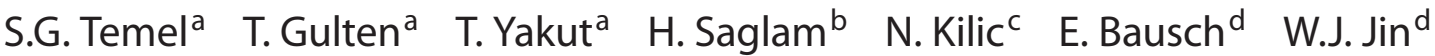 \\ M. Leipoldt ${ }^{d}$ G. Scherer ${ }^{d}$
}

${ }^{a}$ Medical Genetics Department, ${ }^{b}$ Pediatric Endocrinology Department, and ${ }^{c}$ Pediatric Surgery Department, Faculty of Medicine, Uludag University, Bursa, Turkey; ${ }^{d}$ Institute of Human Genetics and Anthropology, University of Freiburg, Freiburg, Germany

\section{Key Words}

Sex determination - Sex differentiation - Sex reversal $\cdot$ SOX9 $\cdot S R Y \cdot 46, X X$ ovotesticular DSD $\cdot 46, X X$ testicular DSD

\begin{abstract}
It is well established that testicular differentiation of the human embryonic gonad depends on the action of the Y-chromosomal gene SRY. However, exceptional cases such as $S R Y$-negative cases of $46, X X$ testicular disorder of sexual development (DSD), and of $46, X X$ ovotesticular DSD document that testicular tissue can develop in the absence of the $S R Y$ gene. These SRY-negative XX sex reversal cases are very rare and usually sporadic, but a few familial cases have been reported. We present a large, consanguineous family with nine affected individuals with phenotypes ranging from $46, X X$ testicular DSD to $46, X X$ ovotesticular DSD, with predominance of male characteristics. Absence of $S R Y$ in peripheral blood was documented by fluorescence in situ hybridization (FISH) and PCR analysis in all nine affected individuals, and by FISH analysis on gonadal sections with testicular tissue in four affected individuals. By quantitative PCR, a duplication of the SOX9 gene was excluded. In addition, as link-
\end{abstract}

age analysis showed that the nine affected members of the family do not share a common SOX9 haplotype, any mutation at the SOX9 locus could be ruled out. Together, these findings implicate a mutation at a sex-determining locus other than $S R Y$ and $S O X 9$ as the cause for the $\mathrm{XX}$ sex reversal trait in this family.

Copyright $\odot 2007$ S. Karger AG, Basel

The process of sex determination in humans, and in mammals in general, has not yet been completely elucidated (Brennan and Capel, 2004; Wilhelm et al., 2006). However, it is clear that this process involves a gene regulatory network in which a Y chromosome-linked master gene, named $S R Y$ (sex determining region of the $\mathrm{Y}$ ), plays a crucial role (Sinclair et al., 1990). SRY induces the undifferentiated embryonic gonad to develop as a testis (Koopman et al., 1991). Although its specific function and downstream molecular targets remain largely unknown, it has been demonstrated in mice that Sry promotes the migration of mesonephric cells to the gonadal rudiment (Capel et al., 1999) and increases the rate of proliferation of coelomic epithelial cells that give rise to Sertoli cell precursors

\section{KARGER}

Fax +41613061234

E-Mail karger@karger.ch

www.karger.com (c) 2007 S. Karger AG, Basel

1661-5425/07/0011-0024\$23.50/0

Accessible online at:

www.karger.com/sxd
Sehime G. Temel, MD, PhD

Uludag University, Faculty of Medicine, Department of Medical Genetics TR-16059 Gorukle Bursa (Turkey)

Tel. +90 2244428400 , ext. 1438 day time, +90 5322361646 night time

E-Mail sehime@uludag.edu.tr 
(Schmahl et al., 2000). These cellular processes finally lead to testis cord formation and to increased gonadal size, the first morphological signs of testicular organogenesis. Hormone production by the embryonic testis is essential for male sexual differentiation: the anti-Müllerian hormone (AMH) induces regression of the Müllerian ducts, and androgens cause development of the Wolffian ducts into epididymis, vas deferens and seminal vesicle, and testicular descent. If the gonads develop as ovaries, the Wolffian ducts regress and the Müllerian ducts become the Fallopian tubes, uterus, and upper part of the vagina.

Two classes of sex reversal syndromes are known in humans that seem to be at odds with the testis-determining function of SRY. One is $46, \mathrm{XY}$ complete gonadal dysgenesis (Swyer syndrome), where testis development fails despite the presence of a Y chromosome and, mostly, of an intact $S R Y$ gene. The other is XX sex reversal, where testicular tissue develops in the apparent absence of $S R Y$. However, in the majority of these latter cases, the femaleto-male sex reversal phenotype can be traced back to the presence of $S R Y$, either due to low level XX/XXY mosaicism, or as a result of an aberrant X-Y interchange with transfer of $S R Y$ to one $\mathrm{X}$ chromosome (de la Chapelle et al., 1990; Ferguson-Smith et al., 1990). But testicular tissue can also develop in subjects entirely lacking a Y chromosome and SRY. Generally, 46,XX sex reversed patients can be classified into two distinct groups. The first group includes individuals with 46,XX ovotesticular disorder of sexual development (DSD) (Hughes et al., 2006) (previously known as 46 ,XX true hermaphrodites), defined by the presence of both testicular and ovarian tissue in the gonads of the same individual, either separately or, more commonly, together as an ovotestis. Individuals with 46 , XX ovotesticular DSD usually have ambiguous external and internal genitalia, depending on the amount of functional testicular tissue present within the gonad. The second group comprises individuals with 46,XX testicular DSD (Hughes et al., 2006) (previously known as 46,XX males), who are characterized by a full development of both gonads as testes without any evidence of ovarian tissue. The phenotype of these individuals varies from a fully normal male to a less complete male phenotype with various degrees of genital ambiguities such as micropenis or hypospadias (Abbas et al., 1990; de la Chapelle et al., 1990; Ferguson-Smith et al., 1990). SRY-negative cases constitute about $90 \%$ of $46, \mathrm{XX}$ ovotesticular DSD cases and also of 46,XX testicular DSD cases with ambiguities of the external or internal genitalia, and about $10 \%$ of 46,XX testicular DSD cases without genital ambiguities (McElreavey et al., 1993).

XX Sex Reversal in the Absence of SRY and of a Mutation at the SOX9 Locus
The occurrence of $S R Y$-negative cases with 46 , XX testicular or ovotesticular DSD, along with the existence of cases with 46,XY complete gonadal dysgenesis with an intact, non-mutated SRY gene, suggests the involvement of X-linked and of autosomal genes in the male, and female, sex determination and differentiation pathway. Over the last 15 years a number of such genes have been identified through positional cloning studies in humans with sex reversal syndromes and in mouse and goat mutants (Brennan and Capel, 2004; Fleming and Vilain, 2004). One of these genes is SOX9, which was originally identified in individuals with the skeletal malformation syndrome campomelic dysplasia which is associated with XY sex reversal (Foster et al., 1994; Wagner et al., 1994). Heterozygous de novo $S O X 9$ mutations identified in these individuals, causing loss of DNA binding or of the transactivation function of this transcription factor, or entire deletion of one copy of SOX9 (Olney et al., 1999; Pop et al., 2004), imply haploinsufficiency as the cause for both the skeletal phenotype and male-to-female sex reversal. Conversely, a duplication of the chromosomal region $17 \mathrm{q} 23 \rightarrow \mathrm{q} 24$ containing SOX 9 has been implicated as the cause for female-to-male sex reversal in a case with 46,XX testicular DSD (Huang et al., 1999). The essential role of SOX9 in mammalian testis development was demonstrated in mice that ectopically express Sox 9 in the female gonad, either due to insertion of a transgene promoter $1 \mathrm{Mb}$ upstream of the Sox9 locus (Bishop et al., 2000; Qin et al., 2004), or from a transgene where expression of Sox9 was driven by the Wt1 regulatory region (Vidal et al., 2001). In both cases, XX embryos showed complete female-to-male sex reversal, demonstrating that Sox9 is sufficient to trigger testis differentiation in the absence of Sry.

$S R Y$-negative $\mathrm{XX}$ sex reversal cases are generally sporadic. A few pedigrees of familial 46,XX testicular DSD or 46,XX ovotesticular DSD, sometimes co-existing in the same pedigree, have been described (reviewed in Sarafoglou and Ostrer, 2000), and absence of SRY has been documented for some of these pedigrees (Kuhnle et al., 1993; Ramos et al., 1996; Slaney et al., 1998; Jarrah et al., 2000; Radi et al., 2005). Here, we present clinical, histological, conventional cytogenetic, molecular cytogenetic and molecular data of nine affected individuals from an extended pedigree who present with a clinical spectrum ranging from $46, \mathrm{XX}$ testicular DSD to $46, \mathrm{XX}$ ovotesticular DSD, with predominance of the male phenotype. 


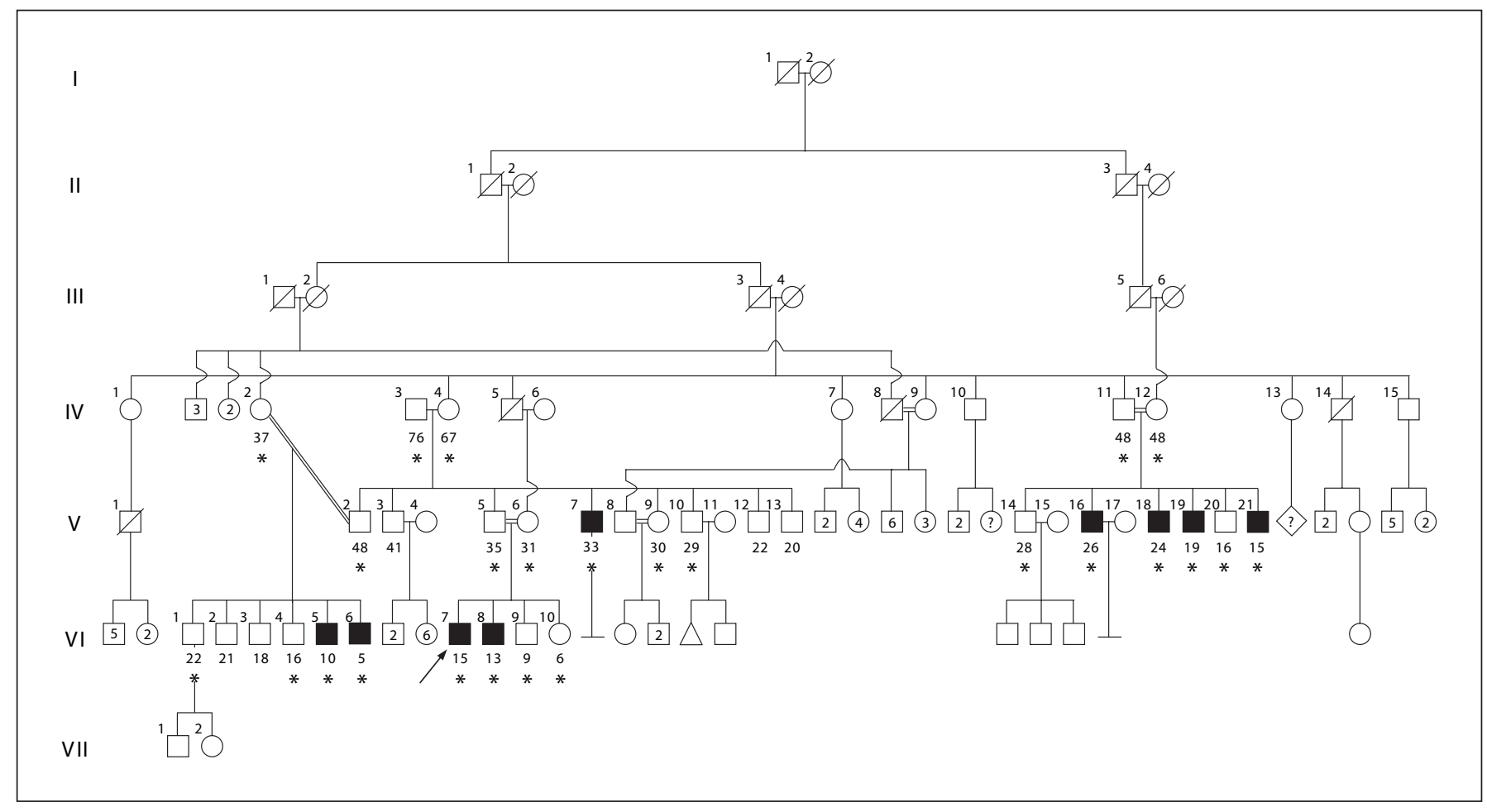

Fig. 1. Pedigree of the family. Filled symbols indicate 46,XX testicular DSD (V-7, V-16, V-18, V-19, VI-5, VI-7) and 46,XX ovotesticular DSD cases (V-21, VI-6, VI-8). The propositus is indicated by an arrow. Numbers below the symbols denote ages. Individuals analyzed by karyotype and $S R Y$ analyses are marked by asterisks.

\section{Case Reports}

All nine affected individuals of Turkish origin described below are from the same pedigree (fig. 1) and share an SRY-negative 46,XX karyotype.

Case 1 (VI-7)

This patient is currently 15 years old and is the one who brought the family to our attention. Two years ago he contacted his doctor for a left undescended gonad and underwent left orchiopexy. He was subsequently sent to our university hospital for detailed analysis. Physical examination revealed a phallus $4-5 \mathrm{~cm}$ in length, penoscrotal hypospadias, severe penile chordee (fig. 2A), female distribution of the pubic hair, and gonads that are bilaterally in the scrotum. Pelvic ultrasound did not detect any Müllerian duct derivatives. Genitoscopy revealed a vaginal orifice $3 \mathrm{~cm}$ proximal to the urogenital sinus. He has a blind-ending vagina. Laparoscopic examination revealed no obvious uterine structure but bilateral ductus deferentes in the inguinal canal. He underwent scrotal exploration and a two-stage hypospadias repair. Gonadal biopsies from both sides showed testicular tissue without any spermatogenic activity (figs. 3A, 4A). Socially, he carries a male name and was brought up as a male. He was given the diagnosis of 46,XX testicular DSD.

\section{Case 2 (VI-8)}

Case 2 is currently 13 years old and was evaluated two years ago around the same time as case 1 . He originally contacted his doctor for the complaint of urination from the penile root. Physical examination revealed a mature phallus 4 to $5 \mathrm{~cm}$ in length, labiascrotal fusion, scrotal hypospadias, and a hypoplastic scrotum with nonpalpable gonads. By scrotal ultrasound no testicles were detected. Genitoscopy revealed a vaginal orifice close to the urogenital sinus. Laparoscopic examination revealed a uterus, tuba uteri and bilateral gonads that appeared as normal ovaries located in normal pelvic position. He underwent hysterovaginasalpingogonadectomy and a two-stage repair of hypospadias. Gonadal histology showed that the left gonad was an immature ovary (fig. $3 \mathrm{C}$ ) and the right gonad an ovotestis. Socially, he carries a male name and was brought up as a male. He was given the diagnosis of 46,XX ovotesticular DSD.

\section{Case 3 (VI-6)}

This patient is currently 5 years old. He was evaluated one and a half years ago because his cousins, cases 1 and 2, had been diagnosed as 46,XX testicular and 46,XX ovotesticular DSD cases, respectively. Physical examination revealed a mature phallus 3 to $4 \mathrm{~cm}$ in length with severe chordee, penoscrotal transposition, bifid scrotum with nonpalpable right gonad and palpable left gonad, and penoscrotal hypospadias (fig. 2B, C). Genitoscopy revealed a vaginal orifice $3 \mathrm{~cm}$ proximal to the urogenital sinus. 

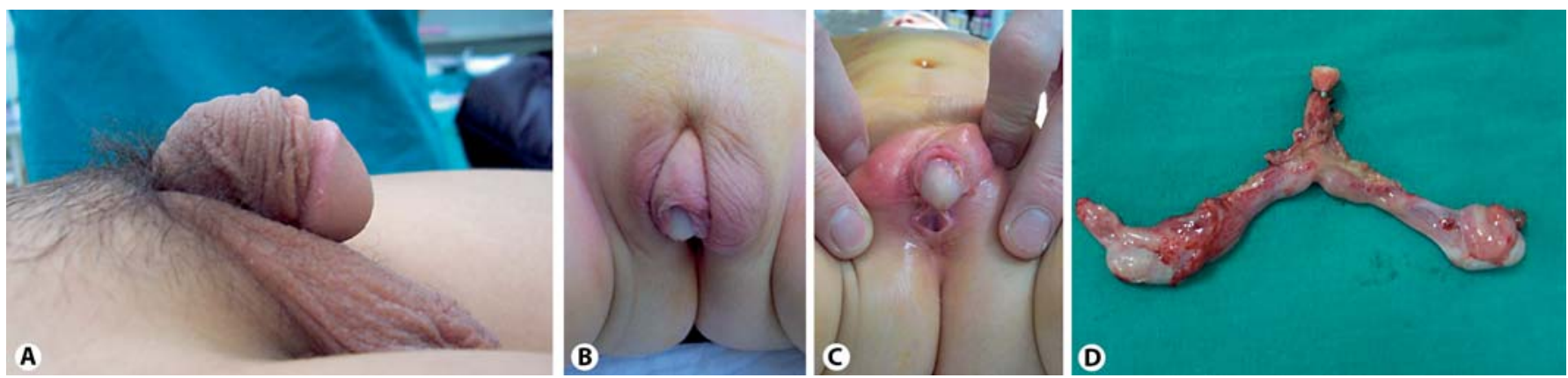

Fig. 2. Appearance of the external and internal genitalia. A Appearance of the external genitalia of the propositus, case 1, showing severe penile chordee. B, C Appearance of the external genitalia of case 3, showing severe chordee, penoscrotal transposition, bifid scrotum with nonpalpable right gonad and palpable left gonad, and penoscrotal hypospadias. D Appearance of the internal genitalia of case 3, showing proximal vagina, uterus, fallopian tubes, ovotestis (left) and ovary (right).
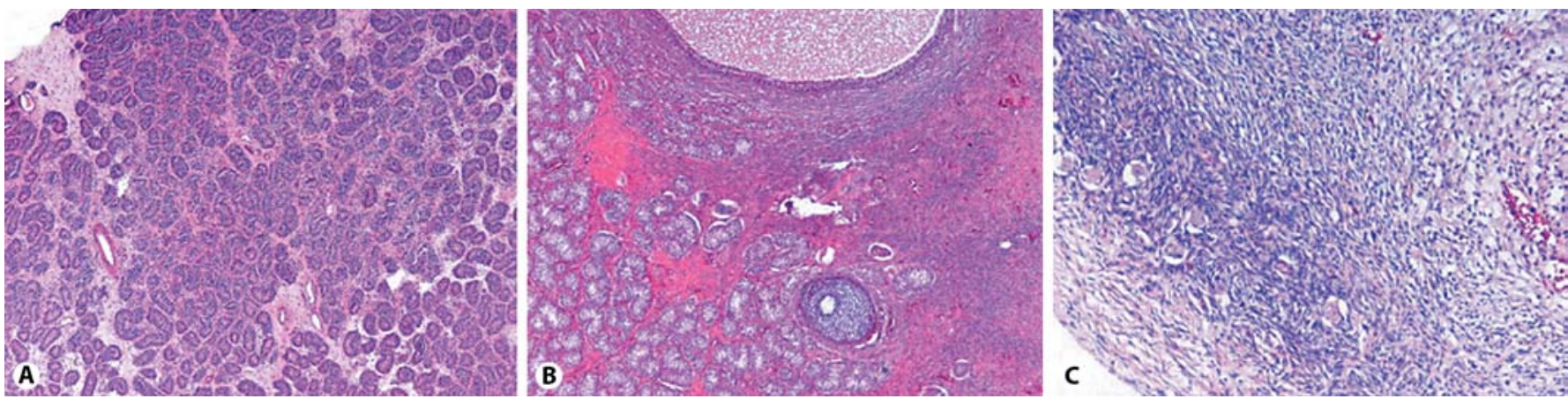

Fig. 3. Low-resolution gonadal histology. A Right gonad of case 1 at age 13, showing testicular morphology. B Right gonad of case 4 at age 13, showing testicular structure at lower left and ovarian structure at upper right. C Left gonad of case 2 at age 11, showing ovarian morphology. Magnification is $4 \times$ for $\mathbf{A}$ and $\mathbf{B}$, and $10 \times$ for $\mathbf{C}$. HE staining.
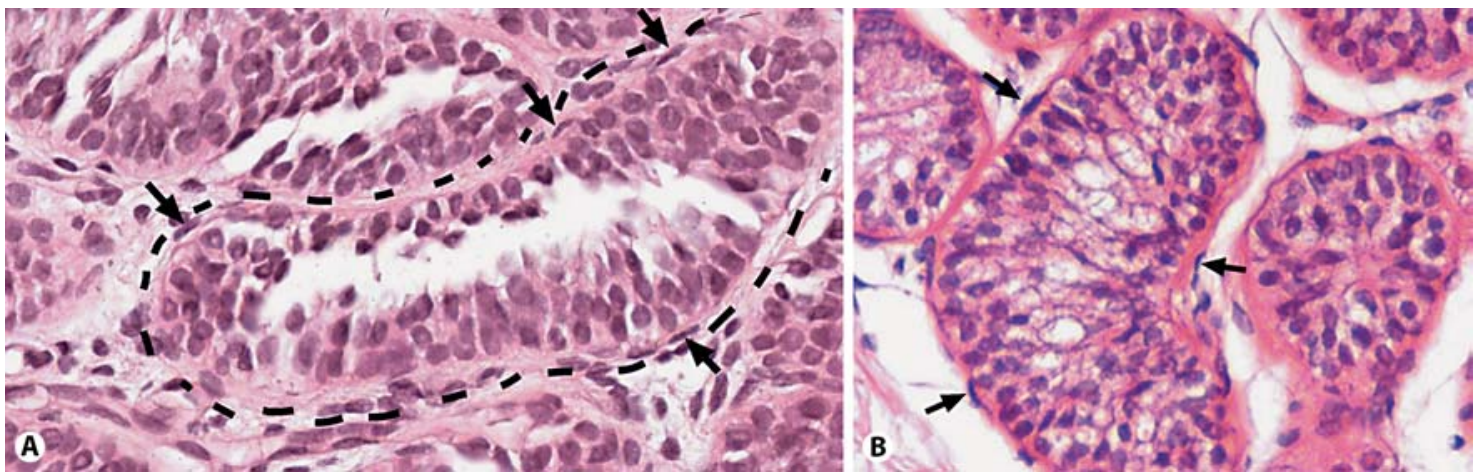

Fig. 4. High-resolution testicular histology. A Seminiferous tubule (dashed outline) from the right testis of case 1, showing Sertoli cell-only phenotype with complete absence of germ cells. B Tubules from the testicular part of the ovotestis of case 4 , showing disorganized structure. Magnification is $100 \times$ for $\mathbf{A}$ and $40 \times$ for $\mathbf{B}$. HE staining. Arrows point to peritubular myoid cells. 
Laparoscopy revealed a uterus, tuba uteri and a right gonad that appeared as a normal ovary located in normal pelvic position. $\mathrm{He}$ underwent hysterosalpingogonadectomy (fig. 2D) and a twostage repair of hypospadias. Gonadal biopsies showed that the left gonad was an ovotestis and the right gonad an ovary. Socially, he carries a male name and was brought up as a boy. He was given the diagnosis of 46,XX ovotesticular DSD.

\section{Case $4(V-21)$}

Case 4 is currently 15 years old and was evaluated two years ago around the same time as cases 1 and 2. As patient 2, he originally went to the doctor for the complaint of urination from the penile root. Physical examination revealed an immature phallus 3-4 cm in length, severe chordee, labioscrotal fusion, perineal hypospadias and a hypoplastic scrotum with nonpalpable gonads. By pelvic ultrasound two ovaries with follicles in the ovarian cortex and a hypoplastic uterus were detected. Genitoscopy revealed a vaginal orifice close to the urogenital sinus. Laparoscopic examination revealed a uterus, tuba uteri and bilateral gonads that appeared as normal ovaries located in normal pelvic position. $\mathrm{He}$ underwent hysterosalpingogonadectomy and a two-stage repair of hypospadias. Gonadal histology showed that the left gonad was an ovary and the right gonad an ovotestis (fig. 3B). The testicular part of the ovotestis consisted of tubules with a disorganized structure (fig. 4B). Socially, he carries a male name and was brought up as a male. He was given the diagnosis of 46 , XX ovotesticular DSD.

\section{Case $5($ V-7)}

Case 5 is currently 33 years old. He is married and has no children. He was originally evaluated one and a half years ago because of infertility. During his physical examination, hypo- and hyperpigmentated areas in his glans penis and proximal glandular hypospadias were noted. He has no penile chordee, a normal penile size, palpable gonads bilaterally, and no gynecomastia. By pelvic ultrasound, no ovaries and no Müllerian duct derivatives were detectable; prostate and seminal vesicle were normal. Scrotal ultrasound revealed a right gonad $25 \times 8 \times 14 \mathrm{~mm}\left(1.5 \mathrm{~cm}^{3}\right)$ in size, and a left gonad $29 \times 8 \times 16 \mathrm{~mm}\left(2.0 \mathrm{~cm}^{3}\right)$ in size. A varicocele in the left gonad and small cystic focal regions in the right gonad were noted. Socially, he is functioning as a male. He was given the diagnosis of 46,XX testicular DSD.

\section{Case 6 (VI-5)}

This patient is currently 10 years old. He was examined one year ago, revealing a penis of normal size with a normal meatus and gonads that were palpable in the scrotum and of normal size. He had female distribution of the pubic hair. By pelvic ultrasound no Müllerian duct derivatives were detected. Laparoscopic examination also did not reveal any Müllerian structures. Gonadal biopsies showed that both the left and right gonad had immature testis histology. Socially, he carries a male name and was brought up as a boy. He was given the diagnosis of 46,XX testicular DSD.

\section{Case $7(V-16)$}

This patient is currently 26 years old. He is married but he has no children. Physical examination, performed one year ago, revealed a normal-sized penis with a megameatus, palpable gonads bilaterally, and absence of gynecomastia. By recent pelvic ultrasound, no ovaries and no Müllerian duct derivatives were detect- able; prostate and seminal vesicle were normal. Scrotal ultrasound revealed a right gonad $13 \times 19 \times 28 \mathrm{~mm}\left(3.5 \mathrm{~cm}^{3}\right)$ in size, and a left gonad $13 \times 17 \times 30 \mathrm{~mm}\left(3.5 \mathrm{~cm}^{3}\right)$ in size, and a varicocele in the left gonad. Socially, he is functioning as a male. He was given the diagnosis of 46,XX testicular DSD.

\section{Case $8(V-18)$}

This patient is currently 24 years old and unmarried. He was originally examined one year ago. He had a penis of normal size, palpable gonads bilaterally, male distribution of the pubic hair, and absence of gynecomastia. By recent pelvic ultrasound, no ovaries and no Müllerian duct derivatives were detectable; prostate and seminal vesicle were normal. Scrotal ultrasound revealed a right gonad $12 \times 17 \times 25 \mathrm{~mm}\left(2.7 \mathrm{~cm}^{3}\right)$ in size, and a left gonad $10 \times 15 \times 27 \mathrm{~mm}\left(2.2 \mathrm{~cm}^{3}\right)$ in size. A hypodense region $(5 \times 3 \times$ $6 \mathrm{~mm}$ ) in the right gonad might indicate an ovotestis or a neoplasia. Socially, he carries a male name and was brought up as a male. He was given the diagnosis of 46,XX testicular DSD.

\section{Case $9(V-19)$}

This patient is currently 19 years old. Physical examination, performed one year ago, revealed a normal-sized penis, distal glandular hypospadias, palpable gonads bilaterally, male distribution of the pubic hair, and absence of gynecomastia. By recent pelvic ultrasound, a small, liquid-filled tubular structure was seen behind the prostate, which continued with a solid structure $4 \times 1 \times 1 \mathrm{~cm}$ in size. The tubular structure could be a utriculus, the solid structure a rudimentary uterus. No structures resembling ovaries were detectable. Scrotal ultrasound revealed a right gonad $10 \times 17 \times 22 \mathrm{~mm}\left(1.9 \mathrm{~cm}^{3}\right)$ in size, and a left gonad $13 \times$ $17 \times 23 \mathrm{~mm}\left(2.5 \mathrm{~cm}^{3}\right)$ in size; cystic focal regions were observed in both gonads. He has a male name and is socially functioning as a male. He was given the diagnosis of 46,XX testicular DSD.

\section{Materials and Methods}

\section{Histological Analysis}

Formalin-fixed and paraffin-embedded gonad tissues of affected individuals were obtained from The University of Uludag, Faculty of Medicine, Department of Pathology. Five-micrometerthick serial sections were cut from each tissue block and stained with haematoxylin and eosin.

\section{Cytogenetic Analysis}

Briefly, peripheral blood lymphocytes were cultivated in RPMI-1640, supplemented with $2 \%$ glutamine, $10 \%$ fetal calf serum, and $2 \%$ PHA-M for $72 \mathrm{~h}$ at $37^{\circ} \mathrm{C}$. Metaphase chromosomes were GTG-banded using standard procedures. Karyotypes were evaluated by two different observers.

\section{Fluorescence in situ Hybridization (FISH) Analysis}

FISH was performed on metaphase spreads and interphase nuclei using peripheral leukocytes fixed on slides. To identify possible gonadal mosaicism, FISH was also performed on paraffin sections of the gonads of four affected individuals. Deparaffinized sections and fixed cells on slides were treated with $0.2 \mathrm{~N}$ $\mathrm{HCl}$ for $20 \mathrm{~min}$ at room temperature, with $8 \%$ sodium thiosulphate at $80^{\circ} \mathrm{C}$ for $30 \mathrm{~min}$, and with $0.5 \%$ pepsin in $0.01 \mathrm{~N} \mathrm{HCl}$ at 
$3^{\circ} \mathrm{C}$ for $20 \mathrm{~min}$, and fixed in $10 \%$ formalin. Probes specific for the X centromere (labeled green) and for SRY (labeled orange) (Vysis, Downers Grove, IL, USA) were used essentially according to the manufacturer's protocol. System filters showed orange signals as red color. The post-hybridization wash was performed twice in $50 \%$ formamide at $47^{\circ} \mathrm{C}$ for $3 \mathrm{~min}$ and then twice in $2 \times$ SSC at room temperature for $3 \mathrm{~min}$. After DAPI counterstaining, metaphase and interphase nuclei showing FISH signals were evaluated and analyzed on a Quips Imaging System (Applied, UK) equipped with a Nikon E 600 (Japan) standard conventional epifluorescence microscope and with a filter set (triple color, DAPI/red/green; dual color, red/green; single red; single green; Vysis, USA).

For SOX9, FISH analysis was performed as described (Borozdin et al., 2004), using cosmid ICRFc105-G1128 (cosG1128) from the SOX9 region as probe (Wirth et al., 1996).

\section{PCR Analysis}

PCR for $S R Y$ was performed using primers AP-1 and AP-2 as described (Jäger et al., 1990). Quantitative PCR analysis to measure gene dosage was performed using an ABI 7900HT Fast RealTime PCR system with SYBR green detection as previously described (Borozdin et al., 2004). As reference amplicons, a 186-bp fragment from $3 \mathrm{p} 26.3$ was amplified with primers F (5'-GCTGCTGTCGTCCCTGGGAACGACC-3') and R (5'-GTGCCAGCCCCACTGCCAGGAACAA- $3^{\prime}$ ), and a 185-bp fragment from 3 p26.2 with primers $F\left(5^{\prime}\right.$-AAGATGGGGATGCAGGGTGGGGAGA-3') and R (5'-GGCAAGGACATCGGCTTAGGTGGCA$\left.3^{\prime}\right)$. Standard curves were generated with serially diluted DNA from a normal female individual. DNA from a 46,XY CD patient with one deleted SOX9 allele (Pop et al., 2004) and from an SRYpositive 47,XXX testicular DSD case (Scherer et al., 1989, case 2) were used as control. The test amplicons from exon 2 (432 bp) and exon 3 (468 bp) of SOX9 were amplified with primers E2-F2 + E2-R4 and E3-F2 (Wagner et al., 1994) + E3-R5 (5'-TTGGTCCTCTCTTTCTTCGGTTATTT-3'), respectively. Test amplicons from $D C X$ were amplified with primers Ex4-F 5'-CGCCCACTGTAGCTTCTACCGAACC-3' and Ex4-R 5'-ACCAACGGCCACCACCCACTATTTA-3' for exon 4 (300 bp), and Ex8-F 5'-GGAACCTCCAGCAGCCAGCTCTCTA-3' and Ex8/2-R 5'-CACCAAGCCATTCAGGAAACTGAGTGC- $3^{\prime}$ for exon 8 (151 bp). Cycling conditions were $50^{\circ} \mathrm{C}$ for $2 \mathrm{~min}, 95^{\circ} \mathrm{C}$ for $15 \mathrm{~min}$, and 40 cycles at $94^{\circ} \mathrm{C}(15 \mathrm{~s}), 58^{\circ} \mathrm{C}(15 \mathrm{~s})$, and $72^{\circ} \mathrm{C}(1 \mathrm{~min})$. For all amplicons, the same conditions were applied. All measurements were done in duplicate and repeated three times. Calculation of the ratios of the test amplicon values relative to the average of the two reference amplicon values was performed as described (Borozdin et al., 2004).

Microsatellite Marker Analysis

Microsatellite markers D17S949,D17S1350, D17S970 and D17S1862 were amplified according to the information provided by the Genome Database (http://www.gdb.org), using fluorescently labeled forward primers and an annealing temperature of $55^{\circ} \mathrm{C}$. PCR products were analyzed on an ABI Prism 310 automated DNA sequencer using Genotyper software version 3.7 (both Applied Biosystems). The largest allele of each marker observed in the pedigree was designated 1 .

XX Sex Reversal in the Absence of SRY and of a Mutation at the SOX9 Locus

\section{Results}

The family with nine XX sex-reversed individuals is of Turkish origin, from a rural area in the Mus province in Eastern Anatolia (fig. 1). Originally, only cases 1 to 5 were studied because they presented with ambiguous genitalia, including hypospadias, or with infertility (case reports, table 1, fig. 2). Unexpectedly, cases 6-9 came to attention when blood samples were collected for linkage analysis, and discordance between gender and sex chromosome status was detected. Genital ambiguities were absent or of milder form in these cases (case reports, table 1). Standard karyotype analysis on peripheral blood showed a 46,XX constitution for all nine patients, and analysis of 20 metaphases by two different observers gave no evidence of mosaicism and of structural or numerical chromosome abnormalities. Gonadal histology (table 1, figs. 3 and 4) allowed us to classify cases 1 and 6 as 46,XX testicular DSD and cases 2 to 4 as 46,XX ovotesticular DSD. As gonadal tissue has been unavailable so far, the remaining four cases have been classified as 46,XX testicular DSD. Because the phenotype of all nine individuals is predominantly male, they have all been raised as males.

Hormonal results of the patients are summarized in table 2. Serum ACTH, cortisol, 17-alpha-hydroxy-progesterone, dihydro-epiandrosterone and androstenedione levels were normal in all cases, indicating normal adrenal steroidogenesis. Serum concentrations of luteinizing hormone (LH) and follicle-stimulating hormone (FSH) in case 6, the only prepubertal case measured, were within the normal range, but they were highly elevated in the four adult cases 5, 7, 8 and 9, confirming their gonadal deficiency. In prepubertal cases, testosterone levels were within the normal prepubertal range. In postpubertal cases, while free testosterone levels were slightly low, total testosterone levels were within normal male range, indicating active testicular steroidogenesis.

To check for the possible presence of SRY, FISH analyses on metaphase and interphase cells from peripheral blood were performed, using an X centromere probe labeled with spectrum green and a locus-specific probe labeled with spectrum orange for the $S R Y$ gene. Two $\mathrm{X}$ chromosome signals, but no signal for $S R Y$ were detected for all nine affected individuals. The same analyses were performed on paraffin sections of gonadal testicular tissue from four affected individuals to check for mosaicism, but again no SRY signal was detected (not shown). PCR analyses for $S R Y$ performed for all affected as well as for several unaffected members of the family (marked 
Table 1. Clinical, cytogenetic, and histological data of the affected individuals

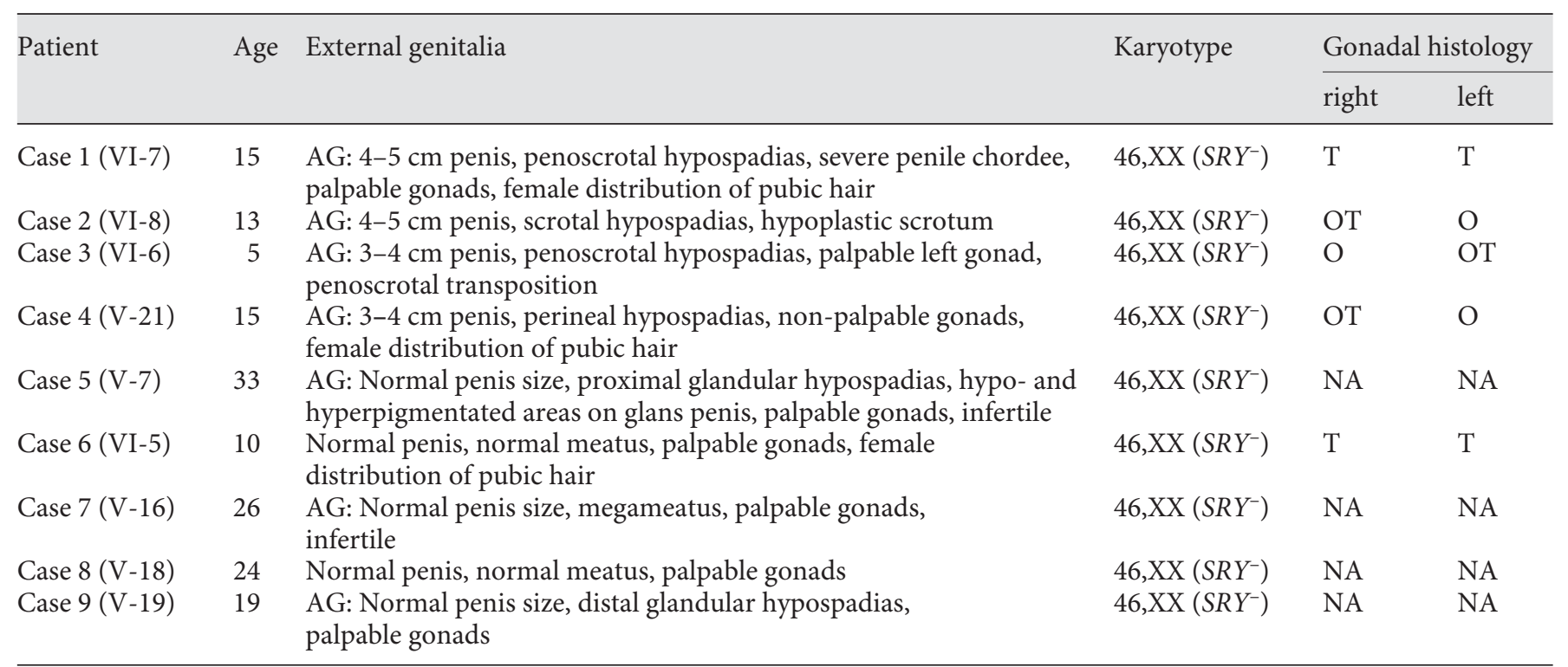

$\mathrm{AG}=$ Ambiguous genitalia; $\mathrm{NA}=$ not analysed $\mathrm{O}=$ ovary; $\mathrm{OT}=$ ovotestis $; \mathrm{T}=$ testis .

Table 2. Hormonal profiles of the affected individuals

\begin{tabular}{|c|c|c|c|c|c|c|c|c|}
\hline \multirow[b]{2}{*}{ Ref. range } & \multicolumn{2}{|c|}{$\begin{array}{l}\text { Follicle stimulating } \\
\text { hormone (IU/l) }\end{array}$} & \multicolumn{2}{|c|}{ Luteinising hormone (IU/l) } & \multicolumn{2}{|c|}{ Total testerone (ng/dl) } & \multicolumn{2}{|c|}{$\begin{array}{l}\text { Free testosterone } \\
(\mathrm{pg} / \mathrm{ml})\end{array}$} \\
\hline & M & $\mathrm{F}$ & M & $\mathrm{F}$ & M & $\mathrm{F}$ & M & $\mathrm{F}$ \\
\hline Tanner 1 & $0.26-3$ & $1-4.2$ & $0.02-0.3$ & $0.02-0.18$ & $<20-50$ & $<20$ & $0.15-0$. & $0.15-0.6$ \\
\hline Tanner 2 & $1.8-3.2$ & $1-10.8$ & $0.2-4.9$ & $0.02-4.7$ & $20-150$ & $7-28$ & & \\
\hline Tanner 3 & $1.2-5.8$ & $1.5-12.8$ & $0.2-5$ & $0.10-12.0$ & $100-320$ & $15-35$ & & \\
\hline Tanner 4 & $2.0-9.2$ & $1.5-11.7$ & $0.4-7$ & $0.4-11.7$ & $200-620$ & $13-32$ & & A \\
\hline Tanner 5 & $2.6-11.0$ & $1.0-9.2$ & $0.4-7$ & $0.4-11.7$ & $350-970$ & $20-38$ & & A \\
\hline Adult & $2.0-9.2$ & & $1.5-9$ & & $350-1030$ & $10-55$ & $8.8-27$ & $0.06-2.57$ \\
\hline Follicular & & $1.8-11.2$ & & $2-9$ & & & & \\
\hline Mid-cycle & & $6-35$ & & $18-49$ & & & & \\
\hline Luteal & & $1.8-11.2$ & & $2-11$ & & & & \\
\hline \multicolumn{9}{|l|}{ Case } \\
\hline 1 (VI-7) & \multicolumn{2}{|c|}{ NM } & \multicolumn{2}{|c|}{ NM } & \multicolumn{2}{|c|}{34} & \multicolumn{2}{|c|}{0.39} \\
\hline $2(\mathrm{VI}-8)$ & \multicolumn{2}{|c|}{ NM } & \multicolumn{2}{|c|}{ NM } & \multicolumn{2}{|c|}{$<20$} & \multicolumn{2}{|c|}{0.72} \\
\hline $3(\mathrm{VI}-6)$ & \multicolumn{2}{|c|}{ NM } & \multicolumn{2}{|c|}{ NM } & \multicolumn{2}{|c|}{$<20$} & \multicolumn{2}{|c|}{0.28} \\
\hline $4(\mathrm{~V}-21)$ & \multicolumn{2}{|c|}{ NM } & \multicolumn{2}{|c|}{ NM } & \multicolumn{2}{|c|}{31} & \multicolumn{2}{|c|}{1.56} \\
\hline $5(\mathrm{~V}-7)$ & \multicolumn{2}{|c|}{44.56} & \multicolumn{2}{|c|}{21.59} & \multicolumn{2}{|c|}{425} & \multicolumn{2}{|c|}{8.72} \\
\hline $6(\mathrm{VI}-5)$ & \multicolumn{2}{|c|}{1.14} & \multicolumn{2}{|c|}{0.34} & \multicolumn{2}{|c|}{23} & \multicolumn{2}{|c|}{0.47} \\
\hline $7(\mathrm{~V}-16)$ & \multicolumn{2}{|c|}{35.77} & \multicolumn{2}{|c|}{13.87} & \multicolumn{2}{|c|}{538} & \multicolumn{2}{|c|}{7.09} \\
\hline $8(\mathrm{~V}-18)$ & 40. & & & & & & & 51 \\
\hline $9(\mathrm{~V}-19)$ & 35. & & & & & & & 78 \\
\hline
\end{tabular}

$\mathrm{NM}=$ Not measured; $\mathrm{NA}=$ not available. 
by asterisks in fig. 1) were in full agreement with the karyotype analyses. These results rule out a cytogenetically undetectable translocation of the $S R Y$ gene as the cause for the XX sex reversal in the pedigree. Thus, the nine affected individuals are all $S R Y$-negative XX sex reversal cases.

As duplication of a segment of 17q including the SOX9 locus has been invoked as the cause for XX sex reversal in an isolated case (Huang et al., 1999), we hybridized a fluorescently labeled cosmid probe, cosG1128, located about $100 \mathrm{~kb} 5^{\prime}$ to SOX9 (Wirth et al., 1996), to metaphase spreads from cases 1 and 5. Only single hybridization signals were seen on both chromosomes 17 (not shown). Because duplications below $2 \mathrm{Mb}$ can not be resolved by FISH, we performed quantitative PCR for cases 1,2 and 4 using amplicons from exon 2 and 3 of SOX9. As controls, DNA from a 46,XY SOX9 deletion case and an SRYpositive 47,XXX testicular DSD case were used, as well as amplicons from the X-chromosomal double cortex (DCX) gene. As shown in table 3, the normalized ratios for both SOX 9 amplicons are very close to 0.50 for the SOX 9 deletion case with one dose of $S O X 9$, reach values of 0.95 and
Table 3. Results of quantitative PCR measurements for SOX9 and $D C X$. The normalized ratios (test amplicon values/average of both reference amplicon values) shown are averages of three measurements, each done in duplicate.

\begin{tabular}{|c|c|c|c|c|}
\hline \multirow[t]{2}{*}{ Patient } & \multicolumn{2}{|l|}{ SOX9 } & \multicolumn{2}{|l|}{$D C X$} \\
\hline & exon 2 & exon 3 & exon 4 & exon 8 \\
\hline 46,XY; SOX9 $\mathrm{Del}^{\mathrm{a}}$ & 0.51 & 0.49 & 0.48 & 0.43 \\
\hline $47, \mathrm{XXX}^{\mathrm{b}}$ & 0.95 & 0.84 & 1.43 & 1.43 \\
\hline Case 1 & 0.97 & 1.08 & 1.05 & 0.98 \\
\hline Case 2 & 1.04 & 1.11 & 1.00 & 1.00 \\
\hline Case 4 & 0.92 & 0.96 & 0.89 & 0.91 \\
\hline
\end{tabular}

a SOX9 deletion case, patient 1 from Pop et al. (2004).

b 47,XXX testicular DSD, case 2 from Scherer et al. (1989).

0.84 for the 47,XXX testicular DSD control sample with two doses of SOX9, and show values around 1.00 for all three XX sex reversal cases. As regards both $D C X$ control amplicons, the presence of one, two or three X chromosomes is readily reflected in the normalized ratios. Taken

\begin{tabular}{|c|c|c|c|c|c|c|c|}
\hline \multicolumn{2}{|c|}{$\begin{array}{l}\text { Dihydroepiandrosterone } \\
\text { sulphate }(\mu \mathrm{g} / \mathrm{dl})\end{array}$} & \multicolumn{2}{|c|}{$\begin{array}{l}\text { 17-alpha-hydroxy- } \\
\text { progesterone (ng/ml) }\end{array}$} & \multicolumn{2}{|c|}{ Androstenedione (ng/dl) } & \multirow{2}{*}{$\begin{array}{l}\begin{array}{l}\text { ACTH } \\
(\mathrm{pg} / \mathrm{ml})\end{array} \\
\mathrm{M}, \mathrm{F}\end{array}$} & \multirow{2}{*}{$\begin{array}{l}\begin{array}{l}\text { Cortisol } \\
(\mu \mathrm{g} / \mathrm{dl})\end{array} \\
\mathrm{M}, \mathrm{F}\end{array}$} \\
\hline M & $\mathrm{F}$ & M & $\mathrm{F}$ & M & $\mathrm{F}$ & & \\
\hline $13-83$ & $19-114$ & $0.03-0.9$ & $0.03-0.82$ & $8-50$ & $8-50$ & $0-100$ & $5-23$ \\
\hline $42-109$ & $34-129$ & $0.05-1.15$ & $0.11-0.98$ & $31-65$ & $42-100$ & & \\
\hline $48-200$ & $32-326$ & $0.10-1.38$ & $0.11-1.55$ & $50-100$ & $80-190$ & & \\
\hline $102-385$ & $58-260$ & $0.29-1.8$ & $0.18-2.3$ & $48-140$ & $77-225$ & & \\
\hline $120-370$ & $44-248$ & $0.24-1.75$ & $0.20-2.65$ & $65-210$ & $80-240$ & & \\
\hline \multirow[t]{4}{*}{$180-450$} & $60-255$ & $0.27-1.99$ & & $75-205$ & & & \\
\hline & & & $0.15-0.7$ & & $85-275$ & & \\
\hline & & & NA & & NA & & \\
\hline & & & $0.35-2.9$ & & $85-275$ & & \\
\hline \multicolumn{2}{|c|}{63.30} & \multicolumn{2}{|c|}{0.49} & \multicolumn{2}{|c|}{2} & 18.00 & 15.30 \\
\hline \multicolumn{2}{|c|}{74.30} & \multicolumn{2}{|c|}{1.28} & \multicolumn{2}{|c|}{12.4} & 18.00 & 11.90 \\
\hline \multicolumn{2}{|c|}{$<15.00$} & \multicolumn{2}{|c|}{0.30} & \multicolumn{2}{|c|}{12} & 16.10 & 8.50 \\
\hline \multicolumn{2}{|c|}{64.90} & \multicolumn{2}{|c|}{1.28} & \multicolumn{2}{|c|}{51} & 10.00 & 4.50 \\
\hline \multicolumn{2}{|c|}{185.30} & \multicolumn{2}{|c|}{2.26} & \multicolumn{2}{|c|}{107} & 10.40 & 9.31 \\
\hline \multicolumn{2}{|c|}{71.41} & \multicolumn{2}{|c|}{0.15} & \multicolumn{2}{|c|}{14.9} & 19.40 & 6.46 \\
\hline \multicolumn{2}{|c|}{252.70} & \multicolumn{2}{|c|}{1.56} & \multicolumn{2}{|c|}{171} & 17.50 & 11.20 \\
\hline \multicolumn{2}{|c|}{322.00} & \multicolumn{2}{|c|}{0.20} & \multicolumn{2}{|c|}{197} & 27.10 & 12.70 \\
\hline \multicolumn{2}{|c|}{347.60} & \multicolumn{2}{|c|}{1.80} & \multicolumn{2}{|c|}{100} & 20.30 & 19.20 \\
\hline
\end{tabular}


Fig. 5. Exclusion of the SOX9 locus by haplotype analysis. A partial pedigree of the family is shown (see fig. 1) together with haplotypes generated from analysis of four microsatellite markers spanning the SOX 9 locus. Note that the 46,XX testicular DSD and 46,XX ovotesticular DSD cases (filled symbols) do not share a common haplotype.

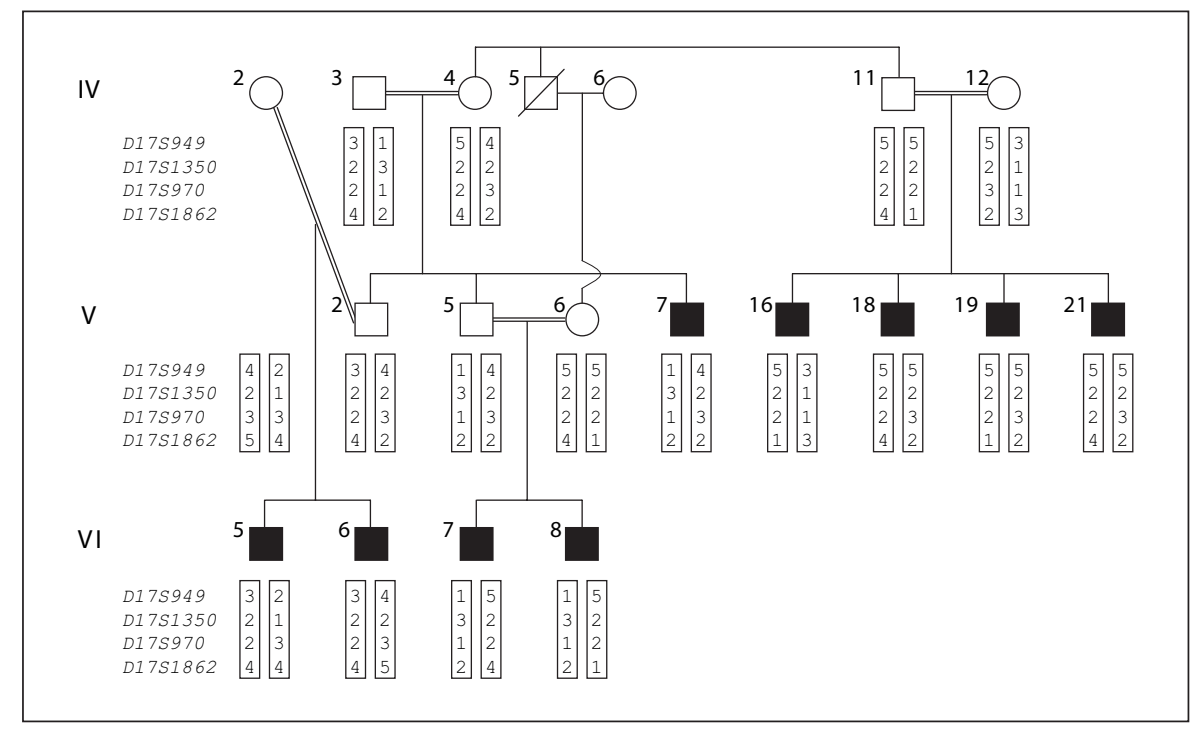

together, the quantitative PCR data do not support the hypothesis that a SOX9 duplication, neither on one nor on both chromosomes 17, is causing the XX sex reversal in the family.

Genetic exclusion of involvement of the SOX9 locus in the XX sex reversal phenotype seen in the family was obtained by linkage analysis. Four microsatellite markers were used, located at chromosome 17 sequence coordinates $65.98 \mathrm{Mb}$ (D17S949), 66.60 Mb (D17S1350), $66.97 \mathrm{Mb}$ (D17S970) and 68.84 Mb (D17S1862); SOX9 is at coordinate $67.63 \mathrm{Mb}$ (UCSC Genome Browser March 2006 Assembly). As the XX sex reversed members of the pedigree do not share a common haplotype at the SOX9 region (fig. 5), any mutation at the SOX9 locus, be it duplication or any other type of mutation, can be excluded.

\section{Discussion}

In this study, we report nine cases of SRY-negative individuals from the same extended family with a phenotypic variation from 46, XX testicular DSD to 46 , XX ovotesticular DSD, who predominantly presented with male characteristics. To our knowledge, this is the largest number of XX sex reversed individuals from a single pedigree reported so far. Due to the lack of gonadal histology, four of the nine individuals have been classified as cases of $46, \mathrm{XX}$ testicular DSD. The scrotal ultrasound findings of small cystic focal or of hypodense regions in the gonads of three of these individuals may indicate that the respec- tive gonads are ovotestes, but this needs future verification by histological examination. The coexistence of $46, X X$ testicular DSD with 46,XX ovotesticular DSD cases within the same pedigree has been described in other families (Kasdan et al., 1973; Skordis et al., 1987; Kuhnle et al., 1993; McElreavey et al., 1993; Ramos et al., 1996; Slaney et al., 1998; Jarrah et al., 2000) and indicates that these two phenotypes are alternative manifestations of the same underlying mutation with marked variation in penetrance and expressivity. It is notable that the four postpubertal cases 5, 7, 8 and 9 have not developed gynecomastia, a frequent finding in 46,XX testicular and 46,XX ovotesticular DSD (Ferguson-Smith et al., 1990; Sarafoglou and Ostrer, 2000). This absence of gynecomastia might be attributable to the close-to-normal testosterone levels in all four individuals.

Cytogenetic and molecular studies of peripheral blood samples both showed the absence of the Y chromosome and of $S R Y$ in all nine affected individuals. One mechanism proposed to explain the development of testicular tissue in patients without $\mathrm{Y}$ material in peripheral blood is the presence of cryptic XX/XXY mosaicism in gonadal tissue. In fact, hidden gonadal mosaicism for the $S R Y$ gene has been shown to be the reason for the development of testicular tissue and of the male phenotype in isolated cases with 46,XX testicular DSD (Dardis et al., 1997) or with 46,XX ovotesticular DSD (Jimenez et al., 2000). Although this possibility seemed unlikely in the present familial cases, $S R Y$ mosaicism in the testicular tissue has been ruled out in four of the five affected individuals where gonadal tissue was available. 
$\mathrm{XY}$ sex reversal is genetically very heterogeneous. Apart from mutations in the SRY and the SOX9 gene, mutations at more than ten other loci have been implicated in its etiology (reviewed in Brennan and Capel, 2004; Fleming and Vilain, 2004). In contrast, for SRY-negative XX sex reversal, only three loci have been identified in mammals so far. One is $S O X 9$, duplication of which in a human with 46,XX testicular DSD (Huang et al., 1999) and its ectopic expression in mice (Bishop et al., 2000; Vidal et al., 2001; Qin et al., 2004) each caused XX sex reversal. By quantitative PCR and by linkage analysis, duplication or any other mutation at the SOX9 locus has been excluded in the present family. In the goat, the polled intersex syndrome (PIS) with XX sex reversal is caused by a small deletion affecting expression of the PISRT1 and FOXL2 genes (Pailhoux et al., 2001). XX mice nullizygous for Wnt4 show male differentiation of the internal genitalia, and the gonad has the appearance of a testis but does not form testis cords (Vainio et al., 1999). A focused linkage analysis for the human FOXL2 and WNT4 region will show whether or not mutation at one of these loci segregates with XX sex reversal in the family.

The mode of inheritance of the XX sex reversal phenotype in this family is probably monogenic. In addition, the structure of the pedigree with several consanguineous marriages, the presence of multiple affected individuals in the same sibships, and the unaffected status of the respective parents, all point to an autosomal-recessive mode of inheritance with sex limitation, as homozygous $46, \mathrm{XY}$ individuals will be silent carriers, the mutation being masked by the presence of SRY. However, one observation seems to be not easily compatible with the autosomal recessive hypothesis, which predicts that only $25 \%$ of the XX individuals in an affected sibship should be sex reversed. In fact, of the XX individuals analyzed cytoge- netically and molecularly (marked by asterisks in fig. 1), one out of two (offspring of IV-3 and IV-4), four out of four (offspring of IV-11 and IV-12), two out of two (offspring of IV-2 and V-2) and two out of three (offspring of $\mathrm{V}-5$ and V-6) are affected. This apparent discrepancy may simply be explained by chance and/or ascertainment bias. On the other hand, the frequent preponderance of males in several other sibships of the pedigree is notable (e.g. offspring of IV-8 and IV-9, of IV-15, and of V-1). An autosomal-dominant inheritance with sex limitation is an attractive alternative hypothesis, as the sex reversal trait could have been passed on by related fathers for all affected sibships but one. There, the mother IV-4, who belongs to the extended pedigree, would have passed on the trait but must then have been unaffected due to reduced penetrance. Alternatively, her partner IV-3, who does not belong to the family but who is from the same local area, could be a carrier of such a hypothetical autosomal-dominant mutation. X-linked recessive or dominant inheritance with sex limitation are both improbable, given the structure of the pedigree as shown in figure 1.

Whatever the genetic mechanism underlying the sex reversal trait, the present family provides a rare opportunity to identify a possibly so far unknown gene in human sex determination by a genome-wide linkage analysis.

\section{Acknowledgements}

We are grateful to the family members for their willingness to participate in this study. We thank Martina Pilz for expert technical assistance, Wiktor Borozdin for advice in quantitative PCR, Deborah Morris-Rosendahl for DCX primers, Gerhard Wolff for suggestions in constructing the pedigree, and Tim Strom for helpful comments on the manuscript.

\section{References}

Abbas NE, Toublanc JE, Boucekkine C, Toublanc M, Affara NA, et al: A possible common origin of 'Y-negative' human XX males and XX true hermaphrodites. Hum Genet 84:356-360 (1990)

Bishop CE, Whitworth DJ, Qin Y, Agoulnik AI, Agoulnik IU, et al: A transgenic insertion upstream of Sox9 is associated with dominant XX sex reversal in the mouse. Nat Genet 26:490-494 (2000).
Borozdin W, Boehm D, Leipoldt M, Wilhelm C, Reardon W, et al: SALL4 deletions are a common cause of Okihiro and acro-renal-ocular syndromes and confirm haploinsufficiency as the pathogenic mechanism. J Med Genet 41:e113 (2004).

Brennan J, Capel B: One tissue, two fates: molecular genetic events that underlie testis versus ovary development. Nat Rev Genet 5: 509-521 (2004).

Capel B, Albrecht KH, Washburn LL, Eicher EM: Migration of mesonephric cells into the mammalian gonad depends on Sry. Mech Dev 84:127-131 (1999).
Dardis A, Saraco N, Mendilaharzu H, Rivarola M, Belgorosky A: Report of an XX male with hypospadias and pubertal gynecomastia, $S R Y$ gene negative in blood leukocytes but $S R Y$ gene positive in testicular cells. Hormone Res 47:85-88 (1997).

de la Chapelle A, Hastbacka J, Korhonen T, Maenpaa J: The etiology of XX sex reversal. Reprod Nutr Dev Suppl 1:39s-49s (1990).

Ferguson-Smith MA, Cooke A, Affara NA, Boyd E, Tolmie JL: Genotype-phenotype correlations in XX males and their bearing on current theories of sex determination. Hum Genet 84:198-202 (1990). 
Fleming A, Vilain E: The endless quest for sexdetermining genes. Clin Genet 67:15-25 (2004).

Foster JW, Dominguez-Steglich MA, Guioli S, Kwok C, Weller PA, et al: Campomelic dysplasia and autosomal sex reversal caused by mutations in an SRY-related gene. Nature 372:525-530 (1994).

Huang B, Wang S, Ning Y, Lamb AN, Bartley J: Autosomal XX sex reversal caused by duplication of SOX9. Am J Med Genet 87:349-353 (1999).

Hughes IA, Houk C, Ahmed SF, Lee PA, LWPES/ ESPE Consensus Group: Consensus statement on management of intersex disorders. Arch Dis Child 91:554-563 (2006).

Jäger RJ, Anvret M, Hall K, Scherer G: A human $\mathrm{XY}$ female with a frame shift mutation in the candidate testis-determining gene SRY. Nature 348:452-454 (1990).

Jarrah N, El-Shanti H, Khier A, Obeidat FN, Haddidi A, Ajlouni K: Familial disorder of sex determination in seven individuals from three related sibships. Eur J Pediatr 159:912918 (2000).

Jimenez AL, Kofman-Alfaro S, Berumen J, Hernandez E, Canto P, et al: Partially deleted $S R Y$ gene confined to testicular tissue in a $46, \mathrm{XX}$ true hermaphrodite without $S R Y$ in leukocytic DNA. Am J Med Genet 93:417420 (2000).

Kasdan R, Nankin HR, Troen P, Wald N, Pan S, Yanaihara T: Paternal transmission of maleness in XX human beings. N Engl J Med 288: 539-545 (1973).

Koopman P, Gubbay J, Vivian N, Goodfellow P, Lovell-Badge R: Male development of chromosomally female mice transgenic for Sry. Nature 351:117-121 (1991).

Kuhnle U, Schwarz HP, Löhrs U, Stengel-Ruthkowski S, Cleve H, Braun A: Familial true hermaphroditism: paternal and maternal transmission of true hermaphroditism $(46, \mathrm{XX})$ and XX maleness in the absence of Y-chromosomal sequences. Hum Genet 92: 571-576 (1993).
McElreavey K, Vilain E, Abbas N, Herskowitz I, Fellous M: A regulatory cascade hypothesis for mammalian sex determination: SRY represses a negative regulator of male development. Proc Natl Acad Sci USA 90:3368-3372 (1993).

Olney PN, Kean LS, Graham D, Elsas LJ, May KM: Campomelic syndrome and deletion of SOX9. Am J Med Genet 84:20-24 (1999).

Pailhoux E, Vigier B, Chaffaux S, Servel N, Taourit $\mathrm{S}$, et al: A 11.7-kb deletion triggers intersexuality and polledness in goats. Nat Genet 29:453-458 (2001).

Pop R, Conz C, Lindenberg KS, Blesson S, Schmalenberger B, et al: Screening of the 1 $\mathrm{Mb}$ SOX9 5' control region by array CGH identifies a large deletion in a case of campomelic dysplasia with XY sex reversal. J Med Genet 41:e47 (2004).

Qin Y, Kong LK, Poirier C, Truong C, Overbeek PA, Bishop CE: Long-range activation of Sox9 in Odd Sex (Ods) mice. Hum Mol Genet 13:1213-1218 (2004).

Radi O, Parma P, Imbeaud S, Nasca MR, Uccellatore F, et al: XX sex reversal, palmoplantar keratoderma, and predisposition to squamous cell carcinoma: genetic analysis in one family. Am J Med Genet 138A:241-246 (2005).

Ramos ES, Moreira-Filho CA, Vicente YA, Llorach-Velludo MA, Tucci S Jr, et al: SRY-negative true hermaphrodites and an XX male in two generations of the same family. Hum Genet 97:596-598 (1996).

Sarafoglou K, Ostrer H: Familial sex reversal: a review. J Clin Endocrinol Metab 85:483-493 (2000).
Scherer G, Schempp W, Fraccaro M, Bausch E, Bigozzi V, et al: Analysis of two 47,XXX males reveals $\mathrm{X}-\mathrm{Y}$ interchange and maternal or paternal nondisjunction. Hum Genet 81: 247-251 (1989).

Schmahl J, Eicher EM, Washburn LL, Capel B: Sry induces cell proliferation in the mouse gonad. Development 127:65-73 (2000).

Sinclair AH, Berta P, Palmer MS, Hawkins JR, Griffiths BL, et al: A gene from the human sex-determining region encodes a protein with homology to a conserved DNA-binding motif. Nature 346:240-244 (1990).

Skordis NA, Stetka DG, MacGillivray MH, Greenfield SP: Familial 46,XX males coexisting with familial 46,XX true hermaphrodites in same pedigree. J Pediatr 110:244248 (1987)

Slaney SF, Chalmers IJ, Affara NA, Chitty LS: An autosomal or X-linked mutation results in true hermaphrodites and 46,XX males in the same family. J Med Genet 35:17-22 (1998).

Vainio S, Heikkilä M, Kispert A, Chin N, McMahon AP: Female development in mammals is regulated by Wnt- 4 signalling. Nature 397 : 405-409 (1999).

Vidal VPI, Chaboissier MC, de Rooij DG, Schedl A: Sox9 induces testis development in XX transgenic mice. Nat Genet 28:216-217 (2001).

Wagner T, Wirth J, Meyer J, Zabel B, Held M, et al: Autosomal sex reversal and campomelic dysplasia are caused by mutations in and around the SRY-related gene SOX9. Cell 79: 1111-1120 (1994).

Wilhelm D, Palmer S, Koopman P: Sex determination and gonadal development in mammals. Physiol Reviews, in press (2006).

Wirth J, Wagner T, Meyer J, Pfeiffer RA, Tietze $\mathrm{HU}$, et al: Translocation breakpoints in three patients with campomelic dysplasia and autosomal sex reversal map more than $130 \mathrm{~kb}$ from SOX9. Hum Genet 97:186-193 (1996). 